Article

\title{
Improved Organic Dye Degradation using Highly Efficient MXene Composites
}

\author{
M. Abdullah Iqbal, ${ }^{1}$ S. Irfan Ali, ${ }^{2,3}$ Ayesha Tariq, ${ }^{1}$ Mohammad Z. Iqbal, ${ }^{4}$ Syed Rizwan ${ }^{1 *}$ \\ ${ }^{1}$ Department of Physics, School of Natural Sciences (SNS), National University of Sciences and Technology \\ (NUST), Islamabad 44000, Pakistan. \\ 2Shenzhen Key Laboratory of Advanced Thin Films and Applications, College of Physics and Energy, Shenzhen \\ University, Shenzhen 518060, China. \\ ${ }^{3}$ Key Laboratory of Optoelectronic Devices and Systems of Ministry of Education and Guangdong Province, \\ College of Optoelectronic Engineering, Shenzhen University, Shenzhen 518060, China. $\ddagger$ Contributed equally to \\ this work. \\ ${ }^{4}$ Department of Chemical and Petroleum Engineering, United Arab Emirates University (UAEU), PO Box 15551, \\ Al-Ain, United Arab Emirates. \\ * Correspondence: Syed Rizwan, Email: syedrizwan83@gmail.com; Tel: +92-9085-5599
}

Mohammad Z. Iqbal, Email: mziqbal12@gmail.com

\begin{abstract}
Over the years, scarcity of fresh potable water has increased the demand for clean water. Meanwhile, with the advent of nanotechnology, the use of nanomaterials for photocatalytic degradation of pollutants in wastewaters has increased. Herein, a new type of nanohybrids of La and Mn co-doped bismuth ferrite $\left(\mathrm{BiFeO}_{3}\right)$ nanoparticles embedded into transition metal carbide sheets (MXene) were prepared by a low-cost double solvent sol-gel method, and investigated for their photocatalytic activity. The photoluminescence results showed that pure BFO has highest electron hole recombination rate as compared to all the co-doped BFO/MXene nanohybrids. The larger surface area and higher electron-hole pair generation rate provides suitable environment for fast photo-degradation of organic molecules. The band gap of the prepared nanohybrids was tuned to $1.96 \mathrm{eV}$ having largest $\mathrm{BiFeO}_{3}$ surface area $\left(147 \mathrm{~m}^{2} \mathrm{~g}^{-1}\right)$ reported till date. Moreover, the $\mathrm{BLFO} / \mathrm{MXene}$ and BLFMO-5/Mxene degraded the $92 \%$ organic pollutant from water in dark and remaining in light spectrum as compare to undoped $\mathrm{BFO} / \mathrm{Mxene}$ due to enhancement of the surface area and electron-hole recombination rate upon doping. Therefore, these synthesized nanohybrids could be a promising candidate for photocatalytic applications in future.
\end{abstract}

Keywords: Doped-Ferrites nanoparticles/MXene; Nanocomposites; Photocatalysis; Chemical Etching

\section{Introduction}

With increasing population and industrialization globally, potential risks associated with contaminating potable water streams worldwide have increased tremendously. Different colouring industries discharge various kinds of organic dyes into the fresh water streams, consequently producing wastewaters. With increasing demand of potable water, these organic colouring substances must be treated in order to make water safe to drink. Congo red (CR) is sodium salt of benzidinediazo-bis -1-naphthylamine-4-sulfonic acid [1]. In this study, CR has been selected for this study due to its anionic structure and severe environmental issues. A large number of industries $[1,2]$ such as textiles, printing, dyeing, paper, and plastic industry produce CR effluents which can contaminate the fresh water supply. If metabolized, CR can turn into benzide, a well-known human carcinogen [3]. The treatment of CR-contaminated wastewater can also be complicated due the complex aromatic structure, which resists degradation. Several physical, chemical, and biological methods qualify for the treatment of coloured-waters. These methods include adsorption [4-7], reverse osmosis [8], coagulation [9, 10], biological [11], and photochemical degradation [12] of organic dyes in 
water. Photocatalysis (photochemical degradation) is a low-cost treatment method that uses catalysts in order to accelerate degradation of organic dyes using sunlight. A class of photocatalysts called semiconductor photocatalysts have also been reported for effective degradation of organic compounds in water [12]. Over the years, several semiconductor particles such as $\mathrm{TiO}_{2}$ and $\mathrm{ZnO}_{2}$, were reported for photocatalysis $[12,13]$. However, these materials usually exhibit lower photocatalytic activity which is attributed to wide band-gaps ( $3.2 \mathrm{eV}$ for $\mathrm{TiO}_{2}$ under visible light) in these materials [13-15]. Since the UV and visible lights constitute $3-5 \%$ \& $43 \%$ of the solar light spectrum respectively [13-15], developing new materials which can be used for photocatalysis under visible light irradiation are of great interests. Consequently, bismuth ferrites, $\mathrm{BiFeO}_{3}$ (called $\mathrm{BFO}$ hereafter) is a semiconductor material that can work as a promising candidate for photocatalysis using visible light irradiation due to the narrow band gap $(\sim 2.2 \mathrm{eV})$ [16-18]. The band gap in BFOs can be improved using doping with other ions $[18,19]$, which alternatively can also improve the photocatalytic activity of BFOs under the visible light irradiation. At room temperature, BFOs exhibit rhombohedrally distorted perovskite structure (R3c) [20], with lattice parameters $a_{r h}=3.965 \AA$ and rhombohedral angle of $\alpha_{r h}=89.3-89.4^{\circ}$ [21]. If the unit cell of BFOs is represented by hexagonal frame of reference, then hexagonal lattice parameters are $a_{h e x}=5.58 \AA$, and chex $=13.90 \AA$ [21, 22]. Doping BFOs with other metallic atoms such a Lanthanum (La) and Manganese (Mn) not only affects the lattice structure of BFOs [23, 24] but also magneto-electric coupling can be strongly improved [25-27]. In addition, recently, co-doped BFOs has revealed improved photocatalytic activity $[28,29]$ which is required to degrade pollutants such as the organic dyes in wastewater under UV and visible light irradiation [17]. Furthermore, nanocomposites of $\mathrm{BiFeO}_{3}$ with graphene-derivatives and metal co-doped $\mathrm{BiFeO}_{3}$ have shown improved photocatalytic activity $[19,30]$. With the discovery of graphene in 2004, a two-dimensional (2D) sheet of $\mathrm{sp}^{2}$-hybridized carbon atoms, a new era has emerged with the drive to discover new and unique $2 \mathrm{D}$ materials. The new 2D materials have been proposed to serve for a large number of potential applications [31-33]. These 2D materials gained an enormous attention due to their very high surface area and electronic properties compared to their bulk counterparts. Largely studied 2D materials include graphene [34, 35], boron nitride [36-38], transition metal di-chalcogenides [39, 40], which are essentially derived from 3D layered materials. Recently, a new 2D layered material composed of transition metal carbides and carbonitrides, also called as MXenes, have attracted considerable attraction from the research community [41-44]. The Mxenes are represented by the general formula $\mathrm{M}_{\mathrm{n}+1} \mathrm{X}_{\mathrm{n}} \mathrm{Tx}(\mathrm{n}=1-3)$, where $\mathrm{M}$ stands for an early transition metal such as like $\mathrm{Ti}, \mathrm{Cr}$, and $\mathrm{Mo}, \mathrm{X}$ is either carbon or nitrogen, and $\mathrm{T}$ represents surface functional groups such as $-\mathrm{O},-\mathrm{OH}$, and/or $-\mathrm{F}$. The first reported Mxene was $\mathrm{Ti}_{3} \mathrm{C}_{2} \mathrm{Tx}$, which further led to the synthesis of an additional nineteen potentially important but different variations in MXene family that are considered significant for future nano-electronic devices and catalytic application [42-45].

There have been a few reports on photochemical degradation of organic pollutants using BFOs. For example, Soltani and Lee reported the photo degradation aqueous bisphenol A using nanohybrids of $\mathrm{BiFeO}_{3} /$ reduced graphene oxide (rGO) nanohybrids [46]. A complete degradation of bisphenol A was observed in 70 minutes under visible light irradiation. Wang et al. also reported a complete degradation of bisphenol A using $\mathrm{Bi}_{22} \mathrm{FeO}_{40} / \mathrm{rGO}$ nanocomposites in 180 minutes under similar irradiation [47]. Dai et al. [48] reported a very low 50\% degradation of methyl orange in 6 hours using $\mathrm{BiFeO}_{3} / \mathrm{GO}$ nanohybrid. In this study, we report synthesis of a high efficient nanohybrids from lanthanum (La) and Manganese (Mn) co-doped bismuth ferrite $\left(\mathrm{BiFeO}_{3}\right)$ abbreviated as $\mathrm{BFO}$ nanoparticles embedded into transition metal carbide sheets (MXene), and investigated for their photocatalytic activity against congo red. The nanohybrids were synthesized by a low-cost double sol-gel method. The microstructures and surface morphology of the nanohybrids were studied using $\mathrm{x}$-ray diffraction and $\mathrm{x}$-ray photoelectron spectroscopy, and scanning electron microscopy. The charge carrier-recombination rate of nanohybrids was measured using photoluminescence (PL) technique. The larger surface area and higher electron-hole pair generation rate in nanohybrids provided suitable environment for fast photo-degradation of congo red. A high degradation rate of congo red ( $92 \%)$ was observed compared to undoped BFO/Mxene. 


\section{Results}

\subsection{Structure and Morphology of Nanohybrids}

X-ray diffractometer (XRD) was used to study the phase morphology of the synthesized nanohybrids. The structures of nanohybrids prepared by sol gel method, and nanohybrids of (BLFO, BLFMO-5, BLFMO-10, BLFMO-20 and BLFMO-25)/MXene were studied by $x$-ray diffractometer (XRD) (Figure 1). The pure BFO matches the JCPDS card \# 20-0169 for $\mathrm{BiFeO}_{3}$ structure. All diffraction peaks can be indexed as rhombohedral, corresponding to (012), (104), (110), (006), (202), (024), (116), (112), (018), and (214) reflections, respectively. The doublet peak at $32^{\circ}$ merges into a single peak which shows the transformation of structure from rhombohedral to orthorhombic. Overall the peaks Shifts towards right in curves for $\mathrm{Bi}_{1-\mathrm{LLa}} \mathrm{Fe}_{1-\mathrm{y}} \mathrm{Mn}_{\mathrm{y}} \mathrm{O}_{3}$ is observed compared to the pure $\mathrm{BFO}$, however the dual peaks at $2 \theta=31.6^{\circ}$ and $32.01^{\circ}$ are reduced in intensity and are a bit merged as the concentration of Mn increases [49]. The average particles sizes calculated using Scherrer's formula [50], $D=k \lambda / \beta \cos \theta$ where $D=$ Crystallite size, $\mathrm{k}=$ Debye constant, $\lambda=$ Wavelength of $\mathrm{X}$-ray, $\beta=$ FWHM. For pure BFO, BLFO, BLFMO-5, BLFMO-10, BLFMO-20 and BLFMO-25 are $46.32 \mathrm{~nm}, 33.89 \mathrm{~nm}, 27.68 \mathrm{~nm}, 26.65 \mathrm{~nm}, 2.96 \mathrm{~nm}$ and $30.15 \mathrm{~nm}$ respectively. There is reduction in particle sizes from pure BFO up to BLFMO-20 as Mn doping increases; however larger particles are formed for BLFMO-25.

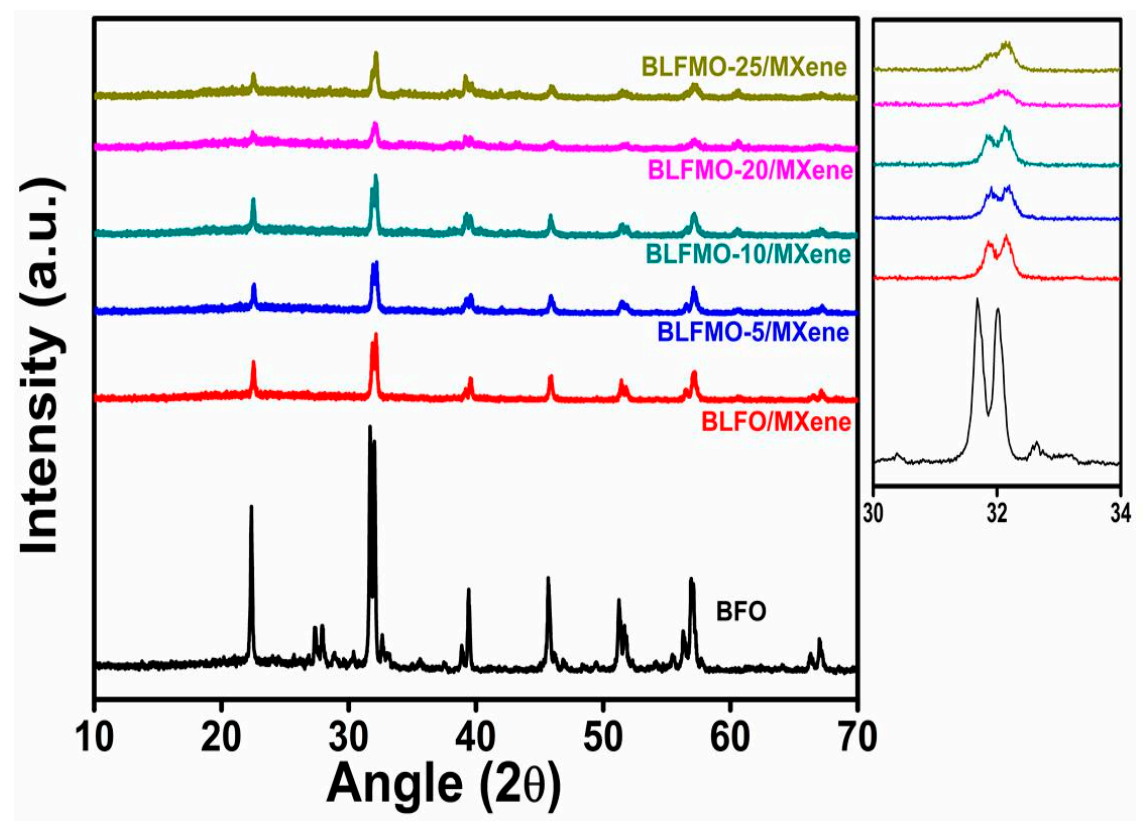

Figure 1. (a) XRD patterns of $\mathrm{Bi}_{1-x} \mathrm{La}_{x} \mathrm{Fe}_{1-y} \mathrm{Mn}_{y} \mathrm{O}_{3}(x=0.1, y=0.0,0.05,0.10,0.20,0.25) / \mathrm{MXene}$ nanohybrids (b) magnified patterns ranging $30^{\circ}$ to $34^{\circ}$.

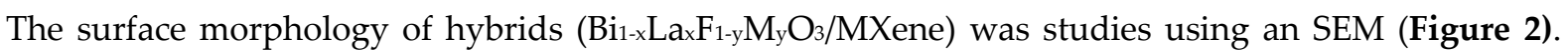
The co-doped BFO particles ( $\mathrm{Bi1}-\mathrm{x} \mathrm{Lax}_{\mathrm{F}} \mathrm{F}_{-\mathrm{y}} \mathrm{M}_{\mathrm{y}} \mathrm{O}_{3}$ ) were observed embedded on the surfaces of MXene sheets. In sample BLFO/MXene, the nanoparticles have covered more of the sheets, whereas in BLFMO/MXene with increasing Mn concentration the BFO particles are embedded lesser on MXene sheets and a few sheets are visible to have lesser attached particles. In BLFO the only dopant is the La, where as in BLFMO the dopants are La and Mn, which might be factor for lesser attached particles. The particle sizes found using cherrer ormula range from 27 - $33 \mathrm{~nm}$ in size, the SEM images are seen against the scale of 200nm, comparatively have a bit larger particle size than in XRD findings. Sample $\mathrm{BLFO} / \mathrm{MXene}$ has a uniform growth of BFO nanoparticles compared to the BLFMO/MXene samples with Mn doping as seen in the image, later it will be shown that the sample BLFO/MXene has photo degradation power twice as sample BLFMO/MXene with different concentrations. Figure 3 shows the photoluminescence spectra (PL) of the $\mathrm{Bi}_{1-\mathrm{x}} \mathrm{Lax}_{x} \mathrm{Fe}_{1-\mathrm{y}} \mathrm{Mn}_{\mathrm{y}} \mathrm{O}_{3} / \mathrm{MXene}$ nanohybrids. All the samples pure

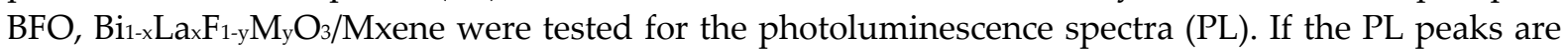
considered to show the recombination rate of the separated charge carriers, then pure $\mathrm{BFO}$ has highest electron hole recombination rate as compared to all the co-doped BFO/MXene nanohybrids. 


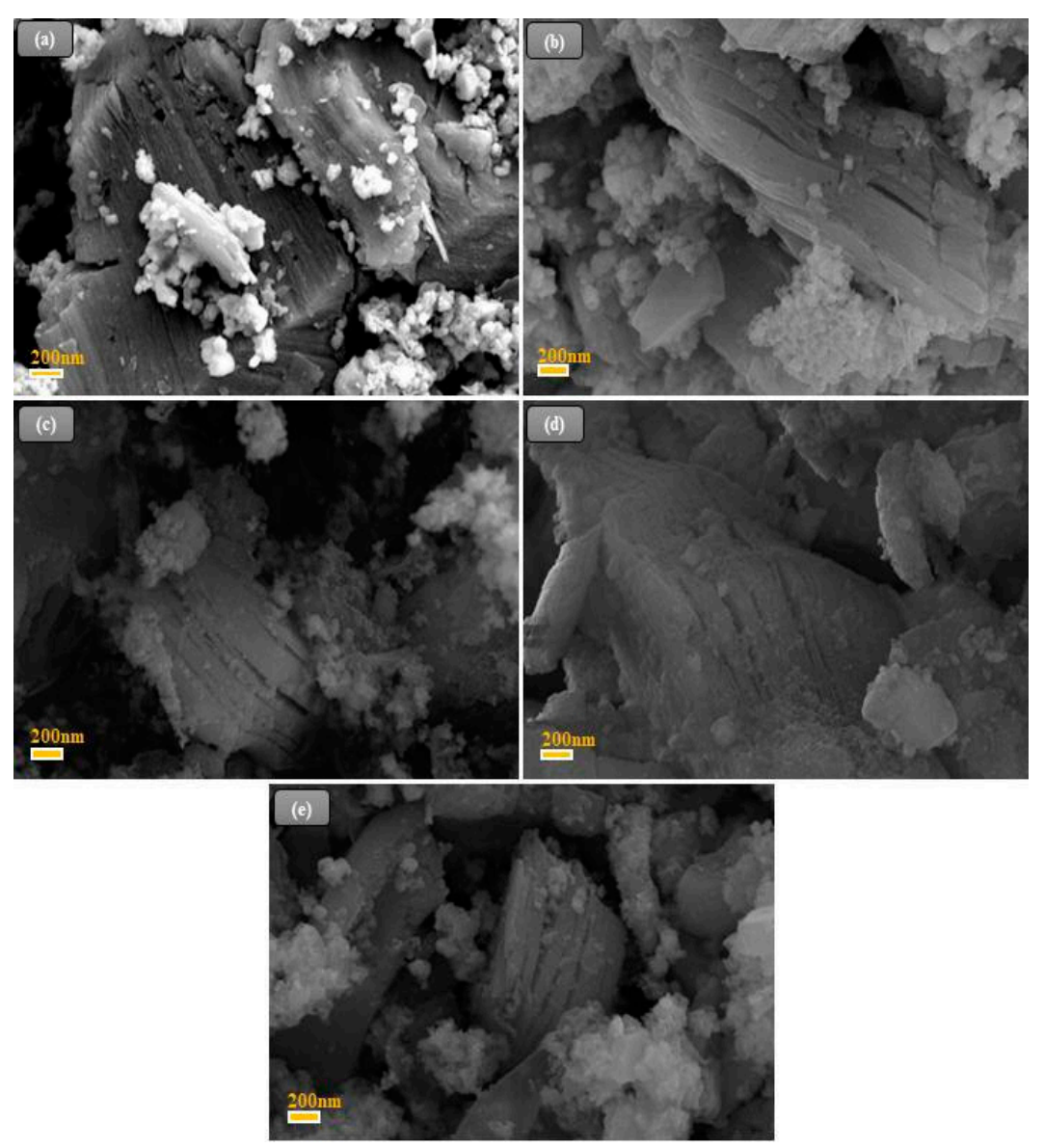

Figure 2. SEM images of (a) BLFO/MXene, (b) BLFMO-5/MXene, (c) BLFMO-10/MXene (d) BLFMO-20/MXene, (e) BLFMO-25/MXene

BLFO/MXene nanohybrid in red having the lowest electron hole recombination rate has best photocatalytic activity; later in this study will be shown the catalytic effects of all the nanohybrids in detail. Lower recombination rate of the $\mathrm{Bi}_{1-x \mathrm{Lax}} \mathrm{Fe}_{1-y} \mathrm{Mn}_{\mathrm{y}} \mathrm{O}_{3} / \mathrm{MXene}$ hybrids than pure $\mathrm{BFO}$ particles might be due to enhanced surface area and larger active points present on MXene sheets. The radicals produced in the $\mathrm{Bi}_{1-\mathrm{x}} \mathrm{Lax}_{\mathrm{Fe}} \mathrm{Fe}_{\mathrm{y}} \mathrm{Mn}_{\mathrm{y}} \mathrm{O}_{3} / \mathrm{MXene}$ nanohybrids are due to activation of nanoparticles; the generation of electron-hole pairs, as the light falls and at first excites the electrons from valence band $(\mathrm{VB})$ to the conduction band $(\mathrm{CB})$. The $\mathrm{CB}$ of semiconductors in reality have more than one energy band as demonstrated in detail by J. Liqiangetal, which claims for the complex photoluminescence mechanisms in semiconductors, and in their comprehensive work on semiconductors they have explained thedependence of photocatalytic activity on the photoluminescence spectra of the materials.[55]The working mechanism of hybrid is such that the charge carriers produced are suddenly spread over the MXene sheets occupying the larger areas of the MXene sheets. The charge carriers spread on these sheets significantly enhances the redox reactions on the surface of MXene sheets; these hybridsBi1-xLaxFe1-y $\mathrm{Mn}_{y} \mathrm{O}_{3} / \mathrm{MXene}$ are considered to have larger surface areas as compared to bare BFO nanoparticles.The proposed structures have significant properties, with the introduction of MXene sheets, two factors are greatly enhanced, i.e. the lower recombination rate of charge carriers and a possibly higher surface area of the nanohybrids. Previous reports on $\mathrm{BFO} /$ graphene nanohybrids have also shown higher surface area and higher photogeneration/lower recombination rate that in turn provided the higher photocatalytic activity. $[16,19,20,44]$ 


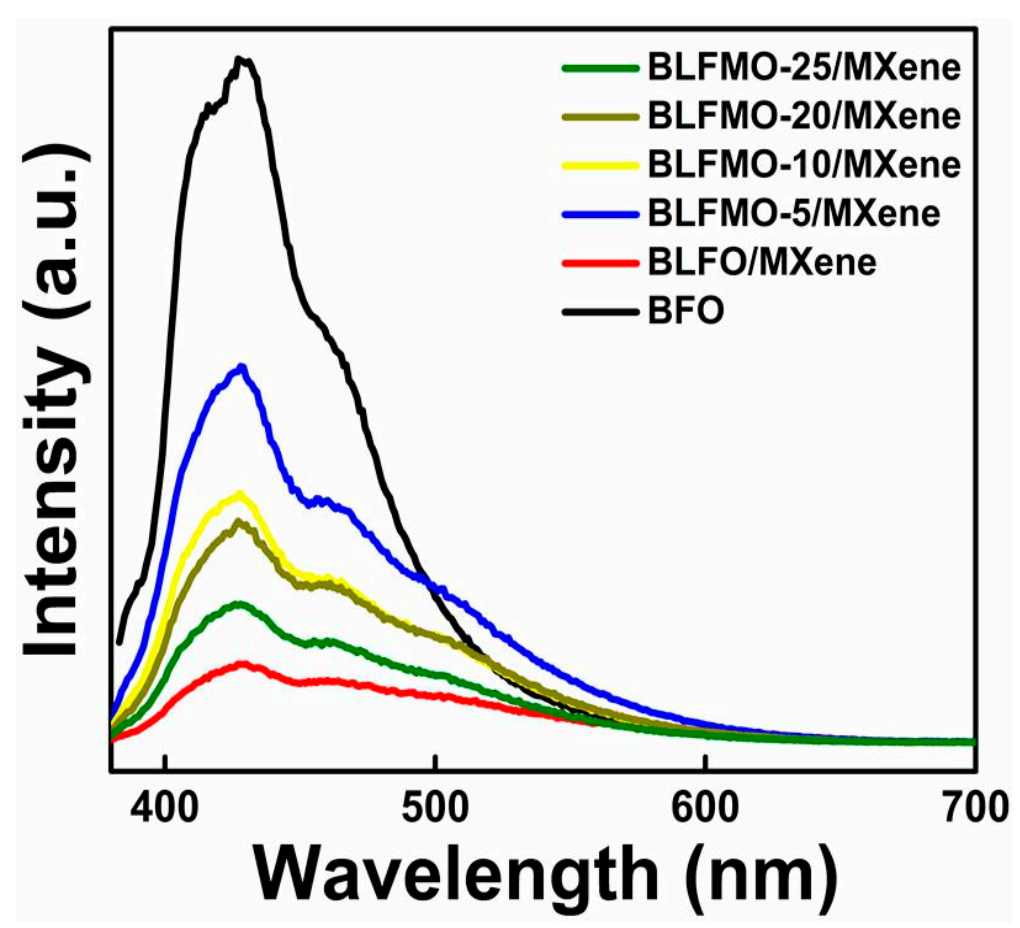

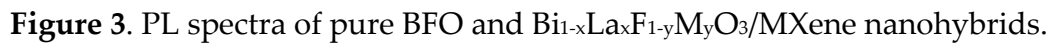

The enhanced photocatalytic activity is due to the higher charge carrier generation/lower electron hole recombination rate and possibly higher surface area, thus providing plenty number ofactivated sites on the sheets for the reactions to take place.

\subsection{X-ray photoelectron spectroscopy (XPS)}

For the confirmation of elemental composition of the newly proposed hybrid structure $\mathrm{x}$-ray photoelectron spectroscopy (XPS) has been performed for the sample BLFMO-5/MXene containing the doped La and Mn elements. Figure 4 explains the (XPS) analysis. Figure 4(a) shows the survey spectrum encompassing the elemental peaks of $\mathrm{Bi}, \mathrm{Fe}, \mathrm{O}, \mathrm{Ti}$ and $\mathrm{C}$ in co-doped $\mathrm{BFO} / \mathrm{MX}$ ene nanohybrid. Elements traced in the hybrid structure are discussed in detail hereafter. The spectrum of $\mathrm{Bi} 4 \mathrm{f}$ is spread over a range from 156 to $167 \mathrm{eV}$ as shown in Figure 4(b), the exact sharp peaks calculated at $158.9 \mathrm{eV}$ and $164.2 \mathrm{eV}$ representing the binding energies of $\mathrm{Bi} 4 \mathrm{f}_{7 / 2}$ and $\mathrm{Bi} 4 \mathrm{f}_{5 / 2}$, respectively. Further stating,the $\mathrm{Bi}$ is in the $\mathrm{Bi}^{3+}$ oxidation state.Figure 4(c) shoes the spectrum for $\mathrm{Fe}$,it spreads over a range of $707 \mathrm{eV}$ to $728 \mathrm{eV}$, qualifying sharp peaks are at $710.7 \mathrm{eV}$ and at $724.4 \mathrm{eV}$, which show the binding energies of $\mathrm{Fe} 2 \mathrm{p}_{3 / 2}$ and $\mathrm{Fe} 2 \mathrm{p}_{1 / 2}$, respectively and those are related to $\mathrm{Fe}^{3+}$ ions. Figure $4(\mathrm{~d})$ is for the spectrum of oxygen element in the hybrid, the peak spreads from $528 \mathrm{eV}$ to $534 \mathrm{eV}$; the exact binding energy for $\mathrm{O} 1 \mathrm{~s}$ lies at the sharper peak at $529.8 \mathrm{eV}$ which agrees to the binding energy of Fe-O bond.[19] Figure 4(e) shows the spectrum for the carbon C 1s bond, the sharp peak is traced at $284.8 \mathrm{eV}$ as seen which can be deconvoluted into two peaks for $\mathrm{C}-\mathrm{C}$ and $\mathrm{C}-\mathrm{O}$ bonds but not described in figure. ${ }^{[21,58]}$ The presence of elements are justified with the binding energies traced in the hybrid structure' XPS spectrum. Supporting the fact that a successful hybrid has been formed between the co-doped BFO nanoparticles and Mxene nano sheets

\subsection{Diffusive Reflectance Spectroscopy of Nanohybrids}

The light absorption properties of of BLFM/MXene nanohybrids were investigated via diffuse reflectance UV (DR-UV) spectroscopy. Band gap energies (EвG) were calculated from the extrapolation of the linear range obtained from modified Kubelka-Munk function $[\mathrm{F}(\mathrm{R}) \mathrm{h} v]^{0.5} \mathrm{vs}$. photon energy, $\mathrm{h} v$ [51]. Significant band gap narrowing was observed for BLFM/MXene nanohybrids in comparison to the bare BFO nanoparticles. EвG of bare BFO nanoparticles were given as $2.04 \mathrm{eV}$, in good agreement with literature values $[17,19]$. BLFM/MXene composites showed band gaps between $1.3-1.5 \mathrm{eV}$. In 
particular, $1.30 \mathrm{eV}$ was calculated for BLFO/MXene, whereas for BLFM-20/MXene the band gap was $1.48 \mathrm{eV}$ (Figure 5).
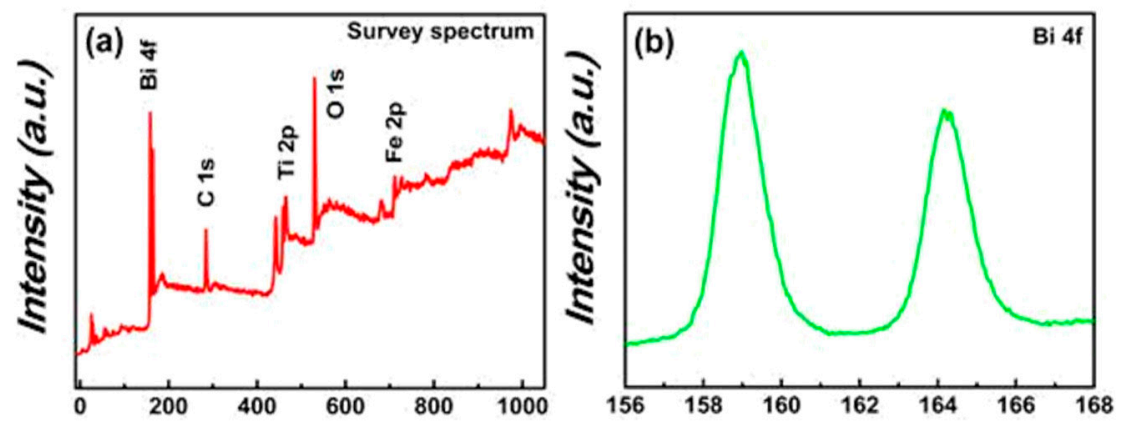

Binding energy (e.V.)

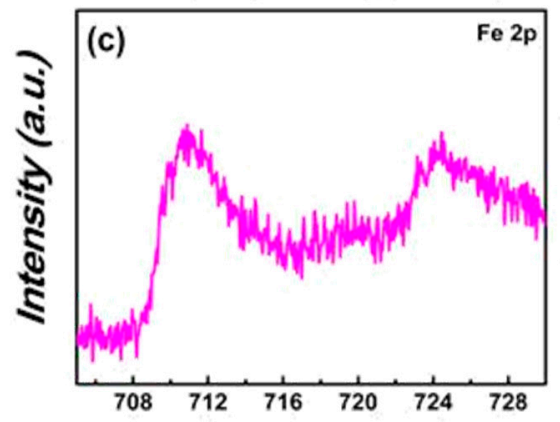

Binding energy (e.V.)

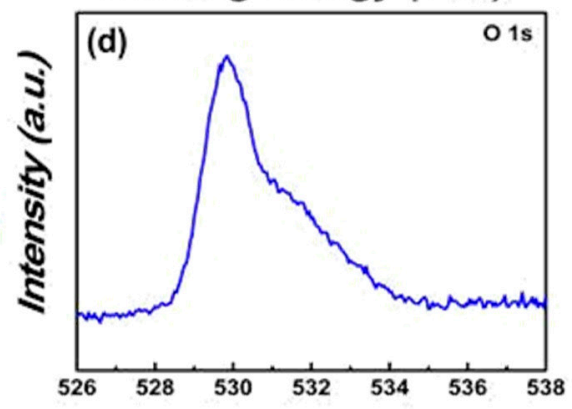

Binding energy (e.V.)

Binding energy (e.V.)

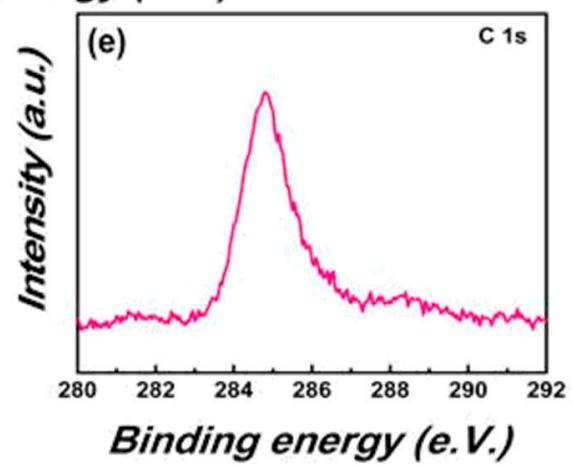

Figure 4. XPS analysisof BLFMO-5sample (a) survey spectrum (b) Bi 4f core levels (c) Fe 2p core levels (d) O 1s core levels (e) C 1s.

Precise Eвя assessment of the rest of MLFM/MXene series was not possible due to the difficulty in discerning the onset of the decrease which may be attributed to small amount of impurity phases [12, 30]. The narrowing of the band gap in nanohybrids in comparison with bare BFO nanoparticles can be explained through the formation of Fe-O-C bonds at the surface of BLFM, which reduces the charge transfer from oxygen ion to Fe ions [30]. Analogous band gap narrowing was observed in literature for graphene/ $\mathrm{BiFeO}_{3}$ nanohybrids [52]. The superior band gap narrowing of $\mathrm{BFLO} / \mathrm{MXene}$ is indicative of better coupling of the BLFO nanoparticles and MXene sheets which was illustrated through SEM images.

\subsection{Photocatalytic Degradation}

The generation of electron-hole pairs by visible light irradiation produced $\mathrm{O}_{2}$ and $\mathrm{OH}$ radicals. These highly active radicals start degrading the organic pollutants present in the water solution, and in turn reduce to harmless by-products $\left(\mathrm{CO}_{2}\right.$ and $\left.\mathrm{H}_{2} \mathrm{O}\right)$. In the general mechanism, photo-exited BLFO/MXene produce electron-hole paired charge carriers as in Equation 1. Trapping sites for electrons are available in large number on the attached MXene sheets which might increase the recombination rate of charge 
carriers as wanted. Once the process starts, the superoxide anion radicals can be produced $\bullet \mathrm{O}_{2}{ }^{-}$, and meanwhile $\bullet \mathrm{OH}^{-}$radicals can be produced by the reaction of $\mathrm{OH}^{-}$with holes.

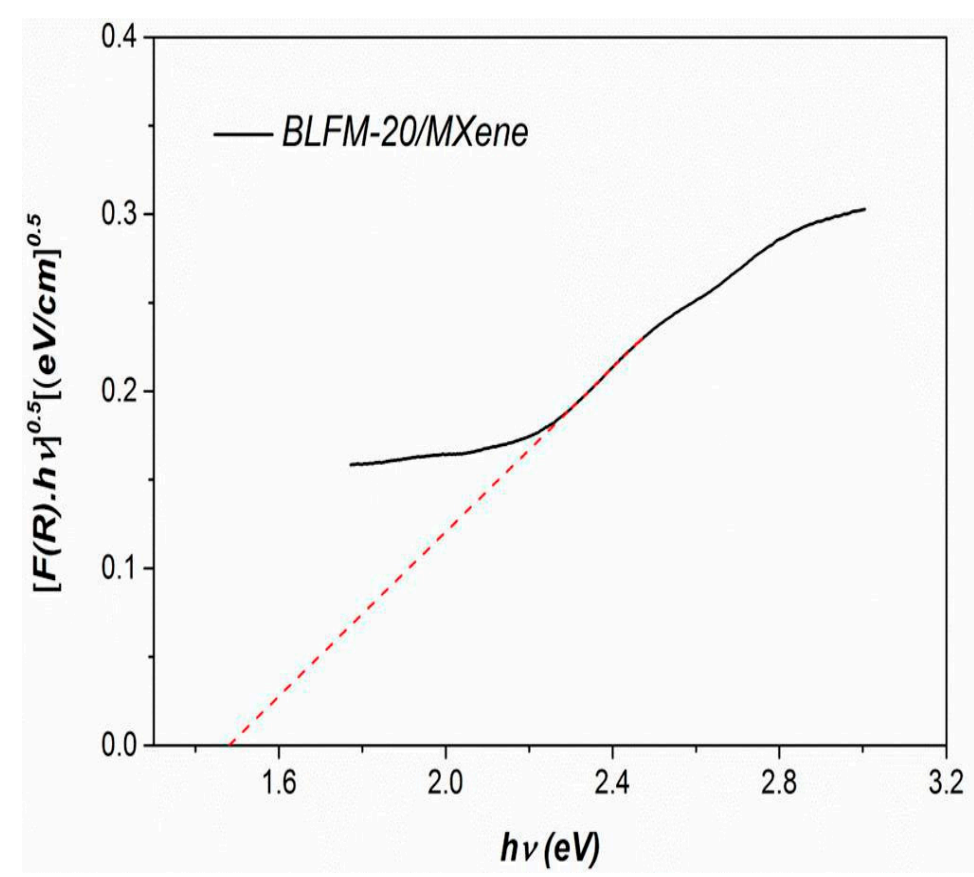

Figure 5 Tauc plot of BLFM-20 Mxene from DR-UV Spectroscopy

As the electrons react with the catalyst, the $\mathrm{H}_{2} \mathrm{O}$ molecules are converted into $\mathrm{OH}$. The radicals produced in the process i.e. $\bullet \mathrm{O}_{2}$ and $\bullet \mathrm{OH}^{-}$, being highly reactive for the organic pollutants such as $\mathrm{CR}$, degrades it to the harmless by-products that are $\mathrm{CO}_{2}$ and $\mathrm{H}_{2} \mathrm{O}$. The mechanism of degradation is given by the equations below:

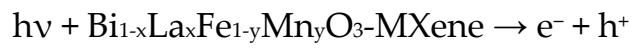

$$
\begin{aligned}
& \text { MXene }+\mathrm{e}^{-} \rightarrow \mathrm{e}^{-}(\text {trap sites MXene) } \\
& \mathrm{e}^{-} \text {(trap sites MXene) }+\mathrm{O}_{2} \rightarrow \cdot \mathrm{O}_{2} \quad- \\
& \mathrm{H}_{2} \mathrm{O}+\mathrm{h}^{+} \rightarrow \bullet \mathrm{OH}^{-} \\
& \mathrm{CR}+\bullet \mathrm{OH}^{-} \rightarrow \mathrm{CO}_{2}+\mathrm{H}_{2} \mathrm{O} \text { (degradation by-products) } \\
& \mathrm{CR}+\bullet \mathrm{O}_{2}-\rightarrow \mathrm{CO}_{2}+\mathrm{H}_{2} \mathrm{O} \text { (degradation by-products) }
\end{aligned}
$$

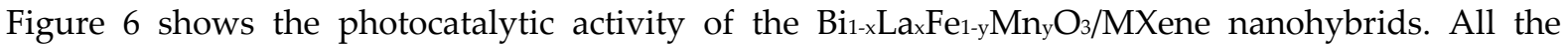
nanohybrids showed improved photocatalytic activity as compared to the bare BFO nanoparticles and Pure MXene. Pure MXene has shown only $12 \%$ dye degradation in 120 minutes. Two samples have shown the best catalytic activity so far: BLFO/MXene and BLFMO-5/MXene. BLFO/MXene reduced the organic dye pollutant about $92 \%$ in dark and BLFMO-5/MXene reduced it in about $93 \%$ in dark, rest completed in light effect. Both of these hybrids proved to be the best reducing catalysts of organic dye (congo red) so far. 


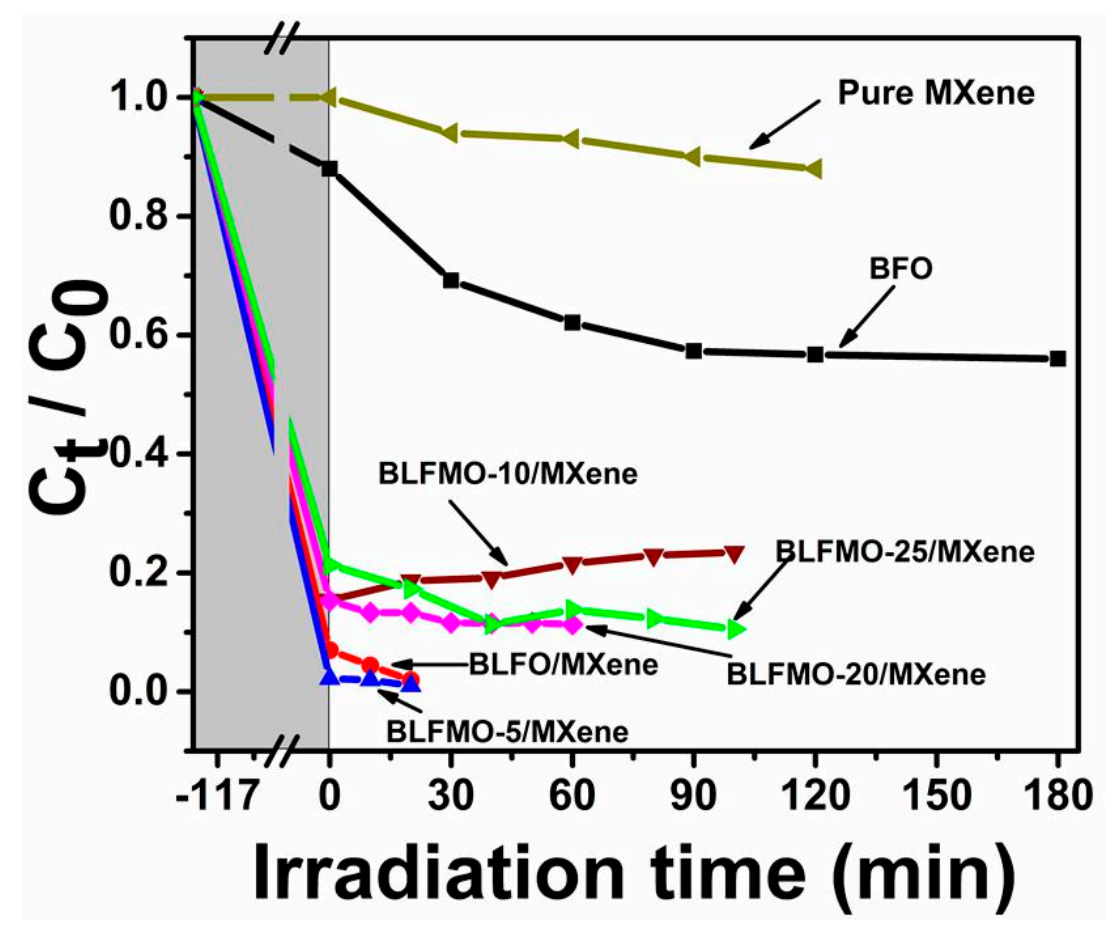

Figure 6 Photocatalytic degradation of CR by Pure MXene, BLFO/MXene and BLFMO/MXene nanohybrids against the time taken.

In about 20 minutes both the samples BLFO/MXene and BLFMO-5/Mxene degraded the organic pollutant in the water. The other three samples BLFMO-10/MXene, BLFMO-20/MXene and BLFMO-25/MXene have lower catalytic activity in dark as well as in the light spectrum, lesser efficient and more time consuming compared to the BLFO/MXene and BLFMO-5/MXene nano hybrids that might be due to the increasing Mn concentration. The improved catalytic activity of these proposed nanohybrids, are due to certain factors i.e. wider absorption of photons, reduced recombination rate of charge carriers and higher redox reactions on the surface of the photocatalyst.

\section{Materials and Methods}

Salts of Bismuth nitrate pentahydrate $\left(\mathrm{Bi}\left(\mathrm{NO}_{3}\right)_{3} .5 \mathrm{H}_{2} \mathrm{O}, 99 \%\right.$ pure), Iron nitrate $\left(\mathrm{Fe}\left(\mathrm{NO}_{3}\right)_{3} .9 \mathrm{H}_{2} \mathrm{O}, 98.5 \%\right.$ pure), ethylene glycol $\left(\mathrm{C}_{2} \mathrm{H}_{6} \mathrm{O}_{2}, 99 \%\right)$, acetic acid $\left(\mathrm{C}_{2} \mathrm{H}_{4} \mathrm{O}_{2}, 99.5 \%\right)$, and Hydrofluoric Acid ( $\left.\mathrm{HF}, 39 \mathrm{wt} \%\right)$ were used as received.

\subsection{Synthesis of MXene sheets}

Multi-layered sheets of $\mathrm{Ti}_{3} \mathrm{C}_{2} \mathrm{Tx}$ were fabricated from pure $\mathrm{Ti}_{3} \mathrm{AlC}_{2}$ (MAX phase) using the following procedure: Approximately $3 \mathrm{~g}$ of $\mathrm{Ti}_{3} \mathrm{AlC}_{2}$ powder was dissolved in $70 \mathrm{~mL}$ of hydrofluoric acid (HF, 39 $\mathrm{wt} \%)$ in a closed Teflon bottle and stirred magnetically for $60 \mathrm{~h}$ at room temperature. Solids were removed from the Teflon bottle, filtered under vacuum, and subsequently washed with DI water and ethanol until a $\mathrm{pH} \sim 6$ was reached. Finally, the washed residue was dried in a convection oven at $60^{\circ} \mathrm{C}$ for $6 \mathrm{~h}$. The residue obtained was Mxene sheets with formula $\mathrm{Ti}_{3} \mathrm{C}_{2}$.

\subsection{Synthesis doped-BFO nanoparticles}

The $\mathrm{Bi}_{1-\mathrm{x}} \mathrm{LaxFe}_{1-\mathrm{yMn}} \mathrm{MnO}_{3}$ (as abbreviated BLFMO, $\mathrm{x}=0.1, \mathrm{y}=0.0,0.05,0.10,0.20,0.25$ ) named here in as BLFO, BLFMO-5, BLFMO-10, BLFMO-20, BLFMO-25) nanoparticles were synthesized using double solvent sol-gel method. Bismuth nitrate pentahydrate and lanthanum nitrate hexahydrate were stoichiometrically were dissolved in equimolar acetic acid and ethylene glycol and magnetically stirred for $90 \mathrm{~m}$ at $40^{\circ} \mathrm{C}$. A mixture of Iron nitrate non-hydrate powder and manganous nitrate solution $(50 \%)$ was also dissolved in acetic acid under constant stirring for $90 \mathrm{~m}$ at $40^{\circ} \mathrm{C}$. Both solutions were mixed in a single flask and stirred for another $180 \mathrm{~m}$ at $40^{\circ} \mathrm{C}$ until a uniform, reddish brown precursor solution $(0.4 \mathrm{M})$ was produced. In order to compensate for Bi loss during heating process, solutions were prepared containing $3 \%$ excess Bi. Ethylene glycol was used to maintain constant 
electro-negativities of iron \& bismuth during the chemical reaction, whereas acetic acid acted as a catalyst to maintain the solution concentration and for controlled chemical reaction during the synthesis process. The as-prepared solution was dried in a convection oven at $80^{\circ} \mathrm{C}$ for $12 \mathrm{~h}$ to obtain a gel which was calcined in a furnace at $600^{\circ} \mathrm{C}$ for $3 \mathrm{~h}$. After calcination was completed, the powder was crushed to get a homogenous fine powder.

\subsection{Synthesis of Mxene-based nanohybrid}

The nanohybrids were fabricated using co-precipitation technique. MXene solution was made in DI water with the molarity of $(0.5 \mathrm{mg} / \mathrm{ml})$, followed by ultrasonication for 10 minutes. The co-doped BFO

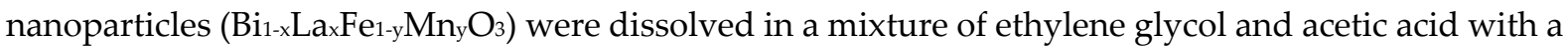
1:1 ratio and $(0.01 \mathrm{M})$ molarity. The $\mathrm{Bi}_{1-x} \mathrm{Lax}_{\mathrm{Fe}} \mathrm{F}_{\mathrm{y}} \mathrm{Mn}_{\mathrm{y}} \mathrm{O}_{3}$ solutions were ultrasonicated for 1 hour at 60 ${ }^{\circ} \mathrm{C}$; then the solutions of $\mathrm{Bi}_{1-\mathrm{LLa}} \mathrm{Fe}_{1-\mathrm{y}} \mathrm{Mn}_{\mathrm{y}} \mathrm{O}_{3}$ were mixed with MXene solutions separately for all

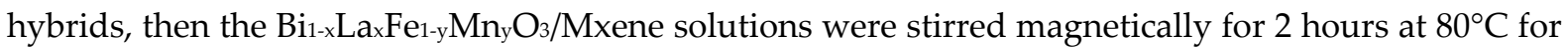
co-precipitation synthesis. The products were washed with DI water several times and were dried at $60{ }^{\circ} \mathrm{C}$ for 3 hours.

\section{Characterization}

Samples were analyzed for their structure using the $\mathrm{X}$-ray diffraction $(\mathrm{XRD}), \mathrm{Cu}-\mathrm{K} \alpha$ radiation source (XRD, Rigaku 2500, Japan). The samples were analyzed for a range of 10-70 degrees. Surface and morphology of hybrids were investigated using field emission scanning electron microscope (FESEM, JEOL7001F). To avoid the charging effect platinum was sputter coated on the nanohybrid before FESEM exposure. Photoluminescence spectroscopy was done to calculate the carrier's generation/recombination rate. Binding energies of elements present in hybrid were checked using X-ray photoelectron spectroscopy (XPS). The solid state diffuse reflectance UV/Vis spectra of the La-, $\mathrm{Mn}$ - co-doped BFO nanoparticles were recorded with a double beam UV/Vis-NIR spectrophotometer (Cary 5000, Varian) equipped with a diffuse reflection accessory (Praying Mantis, Harrick). Baseline correction was achieved using a $\mathrm{BaSO}_{4}$ standard. Approximately, $50 \mathrm{mg}$ of each sample was dispersed in $150 \mathrm{mg} \mathrm{BaSO}_{4}$ for the measurement. The reflectance was converted to the Kubelka Munk function $\mathrm{F}(\mathrm{R})$ with Cary WinUV software.

\section{Conclusion}

$\mathrm{La}$ and $\mathrm{Mn} \mathrm{Co}$-doped $\mathrm{BiFeO}_{3}(\mathrm{BFO})$ nanoparticles as $\mathrm{Bi}_{1-\mathrm{LLax}} \mathrm{Fe}_{1-\mathrm{y}} \mathrm{Mn}_{\mathrm{y}} \mathrm{O}_{3}$ with concentrations $(\mathrm{x}=0.1, \mathrm{y}=$ $0.0,0.05,0.10,0.20,0.25)$ were synthesized using double-solvent sol-gel method. The two-dimensional (2D) MXene sheets were synthesized from their pure MAX phase $\left(\mathrm{Ti}_{3} \mathrm{AlC}_{2}\right)$ by selective etching of Aluminium using Hydrofluoric acid (HF) at room-temperature. The Bi1-x $\mathrm{Lax}_{x} \mathrm{Fe}_{1-y} \mathrm{Mn}_{y} \mathrm{O}_{3} / \mathrm{Mxene}$ nanohybrids were fabricated using co-precipitation technique. Nanohybrids were found to have large electron-hole pairs generation and low recombination time compared to pure BFO nanoparticles. The nanohybridswere further tested for photocatalytic degradation of Congo red and were proved to be the best catalysts in dark and better photo ${ }^{\circ}$ catalysts under visible light irradiation, BLFO/MXene degraded the dye in only 10 minutes of irradiation and BLFMO-5/Mxene in 20 minutes. The hybrids reported are novel and best candidates for catalytic activities, which makes them potential candidates for commercial applications owing to its low-cost synthesis route.

\section{Authors Contribution}

M. Abdullah Iqbal, S. Irfan Ali and Ayesha Tariq carried out experimentation, Muhammad Z. Iqbal helped in manuscript writing and data analysis, Syed Rizwan, designed and supervised the project.

\section{Acknowledgement}

The authors are thankful to Higher Education Commission (HEC) of Pakistan for providing research funding under the Project No.: 6040/Federal/NRPU/R\&D/HEC/2016 and HEC/USAID for financial support under the Project No.: HEC/R\&D/PAKUS/2017/783. The author also thanks School of Natural Sciences (SNS) at National University of Science \& Technology (NUST), Islamabad, Pakistan for partial financial support. Special thanks to DAAD, Germany for providing financial assistance under the project No. 57345771. 


\section{Conflicts of interest}

There are no conflicts of interests between the authors.

\section{References}

1. Walker, G.; Hansen L.; Hanna J-A.; Allen S-J.; Kinetics of a reactive dye adsorption onto dolomitic sorbents. Water Research 2003, 37(9), 2081-2089.

2. Flavio Pavan, A.; Silvio Dias, L-P.; Eder Lima C.; Edilson Benvenutti, V.; Removal of Congo red from aqueous solution by anilinepropylsilica xerogel. Dyes and Pigments 2008, 76(1), 64-69.

3. Mall, I-D.; Srivastava, V-C.; Mishra I-M.; Removal of congo red from aqueous solution by bagasse fly ash and activated carbon: kinetic study and equilibrium isotherm analyses. Chemosphere 2005, $61(4), 492-501$.

4. Gupta, V-K.; Agarwal, S.; Saleh, T-A.; Synthesis and characterization of alumina-coated carbon nanotubes and their application for lead removal. Journal of hazardous materials 2011, 185(1) 17-23.

5. Rafatullah, M.; Adsorption of methylene blue on low-cost adsorbents: a review. Journal of hazardous materials 2010, 177(1), 70-80.

6. Iqbal, M-Z.; Abdala, A-A.; Thermally reduced graphene: synthesis, characterization and dye removal applications. RSC Advances 2013, 3(46), 24455-24464.

7. Iqbal, M.Z.; Priyabrata, P.; Moohamad S.; Ahmed A-A.; Efficient removal of different basic dyes using graphene. Desalination and Water Treatment 2017, 68, 226-235.

8. Al-Bastaki, N.; Removal of methyl orange dye and $\mathrm{Na}_{2} \mathrm{SO}_{4}$ salt from synthetic waste water using reverse osmosis. Chemical Engineering and Processing: Process Intensification 2004, 43(12), 1561-1567.

9. Lee, J.-W.; Seung-phil, C.; Ramesh, T.; Wang-geun S.; Evaluation of the performance of adsorption and coagulation processes for the maximum removal of reactive dyes. Dyes and pigments 2006, 69(3), 196-203.

10. Moghaddam, S.-S.; Moghaddam, M.-A.; Arami, M.; Coagulation/flocculation process for dye removal using sludge from water treatment plant: optimization through response surface methodology. Journal of hazardous materials 2010, 175(1), 651-657.

11. Stolz, A.; Basic and applied aspects in the microbial degradation of azo dyes. Applied microbiology and biotechnology 2001, 56(1), 69-80.

12. Irfan, S.; Rizwan S.; Yang, S.; Liangliang L.; Asfandiyar, sajid, B.; Nan, C.-W; The gadolinium $\left(\mathrm{Gd}^{3+}\right)$ and $\mathrm{Tin}\left(\mathrm{Sn}^{4+}\right) \mathrm{Co}$-doped $\mathrm{BiFeO}_{3}$ nanoparticles as new solar light active photocatalyst. Scientific Reports, 2017, 7, 42493-42505.

13. Carenco, S.; David, P.; Cedric, B.; Nicolas M.; Clement S.; Nanoscaled metal borides and phosphides: recent developments and perspectives. Chemical reviews 2013, 113(10) 7981-8065.

14. Tachikawa, T.; Yamashita, S.; Majima, T.; Evidence for crystal-face-dependent $\mathrm{TiO}_{2}$ photocatalysis from single-molecule imaging and kinetic analysis. Journal of the American Chemical Society 2011, 133(18), 7197-7204.

15. Sun, K.; Jing, Y.; Namseok P.; Chun, L.; Yoshio, B.; Wang, D.; Solution synthesis of large-scale, high-sensitivity $\mathrm{ZnO} / \mathrm{Si}$ hierarchical nanoheterostructure photodetectors. Journal of the American Chemical Society 2010, 132(44), 15465-15467.

16. Gore, S.-K.; Santosh, S.; Vijaykumar V.-J.; Patange, S.-M.; Naushad, M.; Rajaram, S.-M.; Kwang, H.-K.; The structural and magnetic properties of dual phase cobalt ferrite. Scientific Reports, 2017, 7, 2524.

17. Gao, F.; Chen. X.-Y.; Yin, K.-B.; Dong, S.; Ren, Z.-F.; Yuan, F.; Yu, T.; Zou, Z.-G.; Liu, J.-M.; VisibleLight Photocatalytic Properties of Weak Magnetic $\mathrm{BiFeO}_{3}$ Nanoparticles. Advanced Materials 2007, 19(19) 2889-2892.

18. Chaturvedi, S.; Das, R.; Poddar, P.; Sulabha, K.; Tunable band gap and coercivity of bismuth ferrite-polyaniline core-shell nanoparticles: the role of shell thickness. RSC Advances 2015 5(30) 23563-23568.

19. Fatima, S.; Irfan, S.-A; Iqbal, M.-Z.; Rizwan, S.; The high photocatalytic activity and reduced band gap energy of $\mathrm{La}$ and $\mathrm{Mn}$ co-doped $\mathrm{BiFeO}_{3} /$ graphene nanoplatelet (GNP) nanohybrids. RSC Advances 2017, 7(57) 35928-35937.

20. Moreau, J.-M.; Michel, C.; Gerson, R.; James, W.-J.; Ferroelectric $\mathrm{BiFeO}_{3} \mathrm{X}$-ray and neutron diffraction study. Journal of Physics and Chemistry of Solids 1971, 32(6) 1315-1320. 
21. Kubel, F.; Schmid, H.; Structure of a ferroelectric and ferroelastic monodomain crystal of the perovskite $\mathrm{BiFeO}_{3}$. Acta Crystallographica Section B: Structural Science 1990, 46(6)698-702.

22. Bucci, J.; Robertson, B.; James, W.; The precision determination of the lattice parameters and the coefficients of thermal expansion of $\mathrm{BiFeO}_{3}$. Journal of Applied Crystallography 1972, 5(3) 187-191.

23. Zheng, X.; Xu, Q.; Wen Z.; Lang, X.; Wu, D.; Qiu, T.; Xu, M.-X.; The magnetic properties of La doped and codoped BiFeOz. Journal of Alloys and Compounds, 2010, 499(1) 108-112.

24. Kothari, D.; Reddy, V.-R.; Ajay, G.; Phase, D.-M.; Lakshmi, N.; Deshpande, S.-K.; Awasthi, A.-M.; Study of the effect of $\mathrm{Mn}$ doping on the $\mathrm{BiFeO}_{3}$ system. Journal of Physics: Condensed Matter 2007, 19(13) 136202.

25. Li, M.; Ning, M.; Yungui, M.; Qibin, W.; Room temperature ferroelectric, ferromagnetic and magnetoelectric properties of Ba-doped $\mathrm{BiFeO}_{3}$ thin films. Journal of Physics D: Applied Physics 2007, 40(6) 1603.

26. Bartkowska, J.; Dynamical magnetoelectric coupling in multiferroic BiFeO3. International Journal of Thermophysics 2011, 32(4) 739-745.

27. Arya, G.; Negi, N.; Effect of In and Mn co-doping on structural, magnetic and dielectric properties of $\mathrm{BiFeO}_{3}$ nanoparticles. Journal of Physics D: Applied Physics 2013, 46(9), 095004.

28. Zhang, Z.; Liu, H.; Lin, Y.; Wei, Y.; Nan, C.-W.; Influence of La doping on magnetic and optical properties of bismuth ferrite nanofibers. Journal of Nanomaterials 2012, 2012, 4.

29. Kanhere, P.; Chen, Z.; A review on visible light active perovskite-based photocatalysts. Molecules 2014, 19(12)19995-20022.

30. Li, Z.; Yang, S.; Yang, C.; Lei, Y.; Guan, Y.; Liu, D.; Nan, C.-W; Significant enhancement in the visible light photocatalytic properties of $\mathrm{BiFeO}_{3}$-graphene nanohybrids. Journal of Materials Chemistry A 2013, 1(3)823-829.

31. Mas-Balleste, R.; Gomez-Navarro, C.; Gomez-Herrero, J.; Zamora, F.; 2D materials: to graphene and beyond. Nanoscale 2011. 3(1) 20-30.

32. Novoselov, K.; Jiang, D.; Schendin, F.; Booth, T.-J.; Khotkevich, V.-V.; Morozov, S.-V.; Geim, A.-K.; Two-dimensional atomic crystals. Proceedings of the National Academy of Sciences of the United States of America 2005, 102(30) 10451-10453.

33. Gupta, A.-T., Sakthivel, Seal, S.; Recent development in 2D materials beyond graphene. Progress in Materials Science 2015, 73, 44-126.

34. Zhu, Y.; Murali, S.; Cai, W.; Li, X.; Suk, J.-W.; Potts, J.-R.; Rouff, R.-S.; Graphene and graphene oxide: synthesis, properties, and applications. Advanced materials 2010, 22(35), 3906-3924.

35. Geim, A.-K.; Graphene: status and prospects. Science 2009, 324(5934), 1530-1534.

36. Chopra, N.-G.; Boron nitride nanotubes. Science 1995, 269(5226) 966.

37. Watanabe, K.-T.; Taniguchi, Kanda, H.; Direct band-gap properties and evidence for ultraviolet lasing of hexagonal boron nitride single crystal. Nature materials 2004, 3(6) 404-409.

38. Song, L.; Ci, L.; Hao, L.; Pavel, B.-S.; Jin, C.; Jie, N.; Alexander G.-K.; Dmitry G.-K.; Jun, L.; Large scale growth and characterization of atomic hexagonal boron nitride layers. Nano letters 2010, 10(8), 3209-3215.

39. Jariwala, D.; Sangwan, V.-K.; Lauhon, L.-J.; Marks, T.-J.; Hersam, M.-C.; Emerging device applications for semiconducting two-dimensional transition metal dichalcogenides. ACS nano 2014, 8(2), 1102-1120.

40. Wang, Q.H., Kourosh, K.-Z.; Kis, A.; Jonathan, N.-C.; Michael, S.-S.; Electronics and optoelectronics of two-dimensional transition metal dichalcogenides. Nature nanotechnology 2012, 7(11), 699-712.

41. Ghidiu, M.; Naguib, M.; Mashtalir, O.; Zhang, B.; Yang, Y.; Billinge, S.-j.-1.; Barsoum, M.-W; Synthesis and characterization of two-dimensional $\mathrm{Nb}_{4} \mathrm{C}_{3}$ (MXene). Chemical Communications 2014, 50(67) 9517-9520.

42. Anasori, B.; Xie, Y.; Beidaghi, M.; Lu, J.; Hosler, B.-C.; Hultman, L.; Kent, P.-R.-C; Gogotsi, Y.; Barsoum, M.-W.; Two-dimensional, ordered, double transition metals carbides (MXenes). Acs Nano, 2015, 9(10), 9507-9516.

43. Naguib, M.; Halim, J.; Lu, J.; Cook, K.-M; Hultman, L.; Gogotsi, Y.; Barsoum, M.-W.; New two-dimensional niobium and vanadium carbides as promising materials for Li-ion batteries. Journal of the American Chemical Society 2013, 135(43), 15966-15969.

44. Naguib, M.; Mashtalir, O.; Carle, J.; Presser, V.; Lu, J.; Hultman, L.; Gogotsi, Y.; Barsoum, M.-W.; Two-dimensional transition metal carbides. ACS nano 2012, 6(2), 1322-1331. 
45. Khazaei, M.; Arai, M.; Sasaki, T.; Ching, C.-Y.; Natarajan, S.-V.; Mehdi, E.; Sakka, Y.; Kawazoe, Y.; Novel electronic and magnetic properties of two- dimensional transition metal carbides and nitrides. Advanced Functional Materials 2013, 23(17), 2185-2192.

46. Soltani, T.; and Lee, B.-K.; Sono-synthesis of nanocrystallized $\mathrm{BiFeO}_{3} /$ reduced graphene oxide composites for visible photocatalytic degradation improvement of bisphenol A. Chemical Engineering Journal 2016, 306, 204-213.

47. Wang, X.; Mao, W.; Wang, Q.; Zhu, Y.; Min, Y.; Zhang, J.; Yang, T.; Yang, J.; Li, X.; Huang, W.; Low-temperature fabrication of $\mathrm{Bi}_{25} \mathrm{FeO}_{40} / \mathrm{rGO}$ nanocomposites with efficient photocatalytic performance under visible light irradiation. RSC Advances 2017, 7(17), 10064-10069.

48. Dai, J.; Xian, T.; Di, L.-J.; Yang, H.; Preparation of $\mathrm{BiFeO}_{3}$-graphene nanocomposites and their enhanced photocatalytic activities. Journal of Nanomaterials 2013, 2013, 1-5.

49. Irfan, S.; Rizwan, S.; Shen, Y.; Tomovska, R.; Zulfiqar, S.; Iliyas, M.-I.; Nan, C.-W.; Mesoporous template-free gyroid-like nanostructures based on La and $\mathrm{Mn}$ co-doped bismuth ferrites with improved photocatalytic activity. RSC Advances 2016, 6(115), 114183-114189.

50. Asuha, S.; Zhou, X.-G.; Zhao, S.; Adsorption of methyl orange and $\mathrm{Cr}(\mathrm{VI})$ on mesoporous $\mathrm{TiO}_{2}$ prepared by hydrothermal method. Journal of Hazardous Materials, 2010, 181(1-3), 204-210.

51. López, R.; Gómez, R.; Band-gap energy estimation from diffuse reflectance measurements on solgel and commercial $\mathrm{TiO}_{2}$ : a comparative study. Journal of sol-gel science and technology 2012, 61(1), 1-7.

52. Li, Z.; Shen, Y.; Guan, Y.; Hu, Y.; Lin, Y.; Nan, C.-W.; Bandgap engineering and enhanced interface coupling of graphene- $\mathrm{BiFeO}_{3}$ nanocomposites as efficient photocatalysts under visible light. Journal of Materials Chemistry A 2014, 2(6), 1967-1973. 